\title{
Convertible Bonds and Stock Liquidity
}

\author{
Jason West ${ }^{1}$ \\ Griffith University
}

17 January 2011

This paper shows that the probability of exercise of convertible bonds issued against a firm's stock directly affects the liquidity of the stock itself. Using the ratio of absolute stock return to its dollar volume as a proxy for stock liquidity I demonstrate that there is a direct and positive relationship between conversion probability and stock liquidity while controlling for firm size, book to market equity value and firm beta. I describe the effect of unlisted convertible debt on the liquidity of listed firms in the US, Korea and Singapore. The effects of conversion probability on stock liquidity are less pronounced for smaller firms, which helps explain time series variations in the liquidity premiums for smaller firms over time. The relationship between convertibles and stock liquidity is mainly attributed to the expected increase in the number of shares available for trade upon conversion and the expected change in the capital structure of the firm.

JEL Classification: G12, G15, C25

Key words and phrases: Liquidity and asset pricing, convertible bonds, liquidity premium

\footnotetext{
${ }^{1}$ Department of Accounting, Finance and Economics, Griffith Business School, Nathan, QLD, Australia, 4111, +61 737354272 (w), email: j.west@griffith.edu.au
} 


\section{Introduction}

This paper examines how the liquidity of a stock changes in response to the anticipated exercise of convertible bonds issued by a firm. In particular, this study proposes that the probability of conversion of a convertible bond issued against a firm's stock is directly and positively related to the liquidity of the underlying stock. The results are consistent with this hypothesis. Results from this study also confirm that the anticipated increase in liquidity is primarily due to the increased volume of shares available for trade.

The illiquidity measure employed for this analysis is the daily ratio of absolute stock return to its dollar volume, averaged over some period, as used in Amihud (2002). The illiquidity measure can be interpreted as the daily price response associated with one dollar of trading volume. While order-based measures of illiquidity using bid-offer spreads and the probability of information based trading can provide a more detailed analysis of market microstructure effects, the illiquidity measure used here serves as a more general estimate of the price impact of conversion probabilities over a longer period.

The results show that both across stocks and over time, the exercise probability of convertible bonds is a decreasing function of expected illiquidity. An increase in the exercise probability of convertible bonds has a positive and highly significant effect on the liquidity of the stock. The tests used here are the temporal effects of the likelihood of conversion on the market liquidity of the underlying stock into which the bonds can be converted. The exercise probability is thus an increasing function of expected stock liquidity.

After establishing a link between the liquidity and exercise probability of convertibles, the underlying cause of the increase in liquidity conditional on the conversion of bonds into equity is addressed. In particular, I propose that increased liquidity can be caused by favourable changes in the debt-capital ratio of firms and also by market expectations of higher volumes of stock available for trade upon conversion. The results show that higher expected volume of stock available for trade is the primary reason for the increased liquidity.

Section 2 introduces the liquidity measure used in this study along with a definition for the probability of conversion that will be employed in the regression. This section also presents the research methodology for detecting a relationship between liquidity and the probability of conversion, stock returns, firm size, book-to-market ratio and beta. Section 3 discusses the methodology. Section 4 presents the results and proposes reasons for the positive relationship between liquidity and the probability of conversion. Section 5 discusses the results. Section 6 offers some concluding remarks.

\section{Cross-sectional Link between Exercise Probability and Liquidity}

Recent research evidence strongly suggests that illiquid assets offer greater returns than otherwise similar liquid assets. While illiquidity is clearly a central component of asset pricing, capturing the essence of what actually defines illiquidity is a more difficult prospect. The effect of convertible instruments on the liquidity of the stock against which they are issued will aid in forming a more comprehensive picture of the 
true character of asset illiquidity. My paper investigates the link between the liquidity of a stock and the exercise probability of a convertible issued against that stock. The results isolate the primary elements that contribute to the liquidity of ordinary shares of firms that issue convertibles against their stock. The value for the cumulative probability distribution function $N\left(d_{2}\right)$ expression as defined in Ingersol (1977) is used as a proxy for the probability of exercise. The general specification estimates includes controls for the size of the firm $\operatorname{Size}_{t}^{i}$, the book-equity ratio $B E_{t}^{i}$ and the firm's beta $\operatorname{Bet}_{t}^{i}$, and is represented as

$$
\operatorname{ILLIQ} Q_{t}^{i}=\alpha_{0}+\alpha_{1} N\left(d_{2}^{i}\right)_{t}+\alpha_{2} \operatorname{Size}_{t}^{i}+\alpha_{3} B E_{t}^{i}+\alpha_{4} \operatorname{Beta}_{t}^{i}+\varepsilon_{i},
$$

For the $i$-th stock, where

$$
d_{2}^{i}=\frac{\ln \left(S_{0}^{i} / X^{i}\right)+\left(r-q^{i}-\left(\sigma^{i}\right)^{2} / 2\right) T}{\sigma^{i} \sqrt{T}},
$$

and $S_{0}^{i}$ is the current value of the stock, $X^{i}$ is the strike price for conversion, $r$ is the continuously compounded risk free rate, $\sigma^{i}$ is the stock price volatility and $N($.$) is the$ cumulative probability distribution function for a variable that is normally distributed with a mean of zero and a standard deviation of one. The illiquidity variable is estimated using

$$
\operatorname{ILLIQ} Q_{t}^{i}=\frac{1}{n_{t}^{i}} \sum_{d=1}^{n_{t}^{i}} \frac{\left|R_{t, d}^{i}\right|}{V_{t, d}^{i}},
$$

where $R_{t, d}^{i}$ and $V_{t, d}^{i}$ are, respectively, the return and dollar volume (in millions) on day $d$ in week $t$, and $n_{t}^{i}$ is defined as the number of valid observation days in week $t$ for stock $i$. The effect of conversion probability, book to market equity and firm beta on illiquidity is examined for a portfolio of firms over time. A cross-section of each firm at each point in time is also conducted by adding a variable to represent the size of the firm to the regression. Firm size as an independent variable is explicitly excluded from the portfolio regression since sub-portfolios grouped by firm size will be examined separately.

The test procedure for the second set of regressions follows the Fama and MacBeth (1973) method. A cross-sectional model is estimated for each week $t=1,2, \ldots$ where weekly values of illiquidity are a function of stock characteristics:

$$
\operatorname{ILLIQ} Q_{t}^{i}=\alpha_{0, t}^{i}+\sum_{j=1}^{J} \alpha_{j, t}^{i} X_{j, t}^{i}+U_{t}^{i} .
$$

$I L L I Q_{t}^{i}$ is the illiquidity defined in equation (3) on stock $i$ in week $t$ and $X_{j, t}^{i}$ is characteristic $j$ of stock $i$ estimated from data in week $t$. The coefficients $\alpha_{j, t}^{i}$ measure the 
effects of stock characteristics on illiquidity and $U_{t}^{i}$ are the residuals. The weekly regressions of model (4) over the period produce 104 estimates of each coefficient $\alpha_{j, t}^{i}$, $j=1, . ., 4$. These weekly estimates are averaged and tests of statistical significance are performed. Below we discuss each of the stock characteristics used in the regressions.

\subsection{Convertible debt instruments}

Convertible bonds are corporate debt instruments issued by a company that gives the holder the right to forgo future principle and/or coupon payments and receive or convert such payments into a specified number of shares in the company's stock, at certain times in the future. In principle, a convertible bond is a hybrid security consisting of a straight bond and a call option on the underlying equity.

Convertible bonds give their holders the ability to share in price appreciation of the company's stock. When first issued, convertible bonds usually offer lower coupon rates than non-convertible ones. Convertibles are therefore a cost-effective method of financing to the issuer. However, the actual return on the convertible bond has the potential to exceed its stated yield to maturity due to the convertibility feature. The straight bond value acts as a "bond floor" because if the stock price remains depressed during the entire holding period, the bond's value is retained. The presence of downside protection makes convertibles attractive to many private and institutional investors searching for yield enhancement securities with a degree of defence against adverse volatility movements.

Convertible bonds tend to be issued by smaller and more speculative companies because it is costly to assess their business risks, and there are concerns that the company's management may not act in the bondholders' interest, see Stein (1992). Convertible bonds often represent unsecured and generally subordinated debt. Usually, the issuer is in a new line of business that makes it difficult for investors to assign a fair discount rate by assessing the probability of business failure or default. The convertibility feature aligns the interests of the holders of convertible bonds with those of the company's management, allowing the investors to profit when the company's share price rises and to minimize losses when its share price falls. Convertible debt is therefore structured to allow managers to obtain financing immediately through a delayed equity offer.

Corporations use convertible debt as a substitute for common equity because it also provides indirect equity financing that mitigates the adverse selection costs associated with direct equity offerings. Stein (1992) refers to this as the 'backdoorequity' hypothesis. In addition, Stein shows that the likelihood of convertible debt issues increases when the costs of either straight debt or common stock issues are high. The backdoor equity hypothesis predicts that convertible bonds are a substitute for common equity and that this substitution is most likely to occur in firms facing significant information asymmetries and high financial distress costs.

The conversion price of a convertible is calculated as the product of the share price on the date of issue of the convertible and the designated conversion premium of the bond at issue. If the stock price is far below the conversion price, the fair value of the convertible bond behaves like the value of a straight bond. If the stock price is far above 
the conversion price, the fair value of the convertible bond behaves like the value of the stock.

I examine the convertible bonds of 107 publicly listed US, Korean and Singaporean firms who have issued non-callable convertible bonds. The conversion premiums of the bonds examined in this study lie in the range of $18-125 \%$ with a median conversion premium of $36 \%$. For a five-year bond the conversion prices for most of the bonds are not unrealistically high.

In general, practitioners value convertible bonds through simultaneously pricing and combining the equity and fixed-income components of the instrument. Valuing convertibles with callable and conversion features prior to maturity can however, be difficult. Unlike most convertible bonds issued, the convertible bonds used in this study are fully convertible at the holder's discretion prior to maturity, mostly after an initial non-conversion period. In all cases the initial non-conversion period constitutes less than $25 \%$ of the entire life of the bond. Furthermore these bonds are not callable by the issuer. This allows us to neatly de-couple the bond and equity option components of the convertible instrument to measure exercise probabilities. The value of the option component of the bond is estimated using contingent claim valuation techniques from Ingersol (1977). The option-like characteristics of convertibles provide a useful measure to use as a proxy for the probability of conversion. More importantly, this measure provides a reasonable estimate for the temporal probability of conversion of each convertible bond because it allows the parameters of the option to change through time.

The bonds used in this study are also held entirely by financial institutions. Each bondholder sold the converted equity within three months of conversion, and in most cases, the stock was sold almost immediately.

\subsection{A measure of illiquidity - ILLIQ ${ }_{t}^{i}$}

In capital markets, investors require securities to have a certain level of liquidity to facilitate the trading of securities without the need for price discounts. Investors therefore may demand a risk premium for securities that do not meet their liquidity expectations and may be willing to accept lower returns for more liquid securities. Studies by Datar, Naik and Radcliffe (1998) and Amihud (2002) established this link.

A perfectly liquid market exists if any amount of a particular asset can be instantaneously converted into a more liquid form and can then be converted back into an asset at no cost. There is no wealth depletion from transaction costs in a perfectly liquid market. In contrast, a perfectly illiquid asset cannot be traded at any price. A liquid market however, is deemed to exist if such a conversion results in so-called minimal transaction costs.

Transaction costs consist of both explicit and implicit costs. Explicit costs generally include the externally imposed costs of executing a transaction such as brokerage commissions and taxes. The implicit costs associated with a transaction, which include bid-offer spreads and market impact costs, generally arise because of regulatory limits, information dissemination, participation and technological constraints. For instance, minimum tick sizes that are artificially large increase transaction costs and act as a disincentive to investors. We will consider only the implicit costs of trading in stocks in this paper. 
Liquidity measures applied in recent research may be divided into two broad categories: trade-based measures and order-based measures. Trade-based measures commonly used include trading volume, trading frequency and turnover ratio. Tradebased measures are simple to calculate using readily available market data and have widespread acceptance particularly among market professionals. Order-based measures have emerged from the proliferation of automated trading systems that allows the use of more order-based liquidity measures. Order-based measures include absolute and relative bid-offer spreads and bid and offer volumes at each price step used to measure the socalled depth of the market. While order-based measures are suitable for intraday liquidity studies, such measures provide limited advantages for observing liquidity over longer frequencies.

It is doubtful that there is a single measure that captures all aspects of stock price liquidity. The trade-based measure of the response of price to order flow first suggested in Kyle (1985) and employed by Amihud (2002) is used in this study as a measure of illiquidity.

The use of this illiquidity measure is applicable in this study for several reasons. An illiquid stock, that is, one that has a high value of $I L L I Q_{t}^{i}$, is one where the stock's price moves a lot in response to little volume. Consistent with this view, Amihud (2002) shows empirically that $I L L I Q_{t}^{i}$ is positively related to measures of price impact and fixed trading costs over the time period in which microstructure data was available. This measure follows the concept of illiquidity proposed in Kyle (1985) which detects the response of price to order flow. Another interpretation of $I L L I Q_{t}^{i}$ is related to the consensus among traders regarding new information, following Harris and Raviv (1993). When a general consensus among investors is obtained concerning the implication of news the stock price changes without necessarily increasing trading volume. If disagreement among traders occurs an increase in trading volume is generally observed. Thus $I L L I Q_{t}^{i}$ can also be interpreted as a measure of consensus belief among investors about new information. While a number of factors contribute to the liquidity of a firm's stock, I propose that the presence of convertible instruments with a high likelihood of conversion will have a positive influence on the stock's liquidity.

\subsection{A measure for the probability of conversion - $N\left(d_{2}\right)$}

Since the intention is to detect a relationship between the probability of exercise of a convertible and the liquidity of the firm's stock, a proxy for the measurement of the likelihood of conversion is required. The most appropriate measure of the probability of exercise of a convertible instrument is to obtain a value for the cumulative probability distribution function $N\left(d_{2}\right)$ expression as defined in Ingersol (1977). The value of a call option under the Black and Scholes framework using risk neutral valuation can be expressed as

$$
c=e^{-r T}\left[S_{0} N\left(d_{1}\right) e^{(r-q) T}-X N\left(d_{2}\right)\right],
$$


where $S_{0}$ is the current value of the stock, $X$ is the strike price for conversion, $r$ is the continuously compounded risk free rate, $\sigma$ is the stock price volatility and $N($.$) is the$ cumulative probability distribution function for a variable that is normally distributed with a mean of zero and a standard deviation of one. In addition,

$$
d_{1}=d_{2}+\sigma \sqrt{T}
$$

where $d_{2}$ is defined in equation (2) assuming a continuous dividend yield $q$. This approach relies on the general assumptions underlying the Black and Scholes (1973) and Merton (1973) models.

The Black and Scholes model is intuitively understood when broken down into the two main parts. The first element of the equation $S_{0} e^{-q T} N\left(d_{1}\right)$ derives the expected benefit from acquiring the stock outright. This is equivalent to multiplying the stock price adjusted for the continuous dividend yield $S_{0} e^{-(r-q) T}$ by the change in the call premium, with respect to a change in the underlying stock price $N\left(d_{1}\right)$. The $N\left(d_{1}\right)$, commonly known as the delta, measures the sensitivity of the convertible bond to its underlying stock value.

The second component of the model $X e^{-r T} N\left(d_{2}\right)$ is the present value of paying the exercise price on the expiration day. In other words $X e^{-r T} N\left(d_{2}\right)$ is the present value of the strike price times the probability that the strike price will be paid. While this view is relevant for share options, the underlying principles of the formula can also be applied to compute the probability of conversion of a convertible bond that has a conversion price $X$.

The value $N\left(d_{2}\right)$ serves as a useful proxy for the probability of exercise since it dynamically incorporates the risk free rate, volatility of the underlying stock, dividend yield, time to maturity of the convertible instrument and the conversion price. Intuitively, under the Black and Scholes model the expression $N\left(d_{2}\right)$ is the probability that the option will be exercised in a risk neutral world. The fair value of a convertible instrument however, is not strictly obtained in a risk neutral world, and is typically priced using a numerical approximation such as a trinomial tree using a combination of both risk free and credit adjusted rates. The fair value of a convertible instrument is obtained in practice using a linear combination of the risk free rate and a credit spread as the appropriate discount factor. Therefore, while the expression for $N\left(d_{2}\right)$ cannot strictly be used to assess the true probability of exercise under either the risk neutral or real world measure, it serves as a useful proxy for the overall likelihood of exercise since it incorporates changes in dividends, volatility and time.

The main advantage in using this approach is that the inputs can be synchronised to each point in the data. The Black and Scholes formula rests on the assumptions of constant volatility, dividend yield and risk free rate through time. While this provides only approximate fair values for stock options we will ignore the minor limitations of the Black and Scholes model in this study. In any case, the value obtained for $N\left(d_{2}\right)$ is only an approximate representation of the probability of conversion and does not fully reflect the set of decision variables typically applied by a bondholder. 
It is important to include all factors that may affect the probability of conversion using the most recent observations in the market. For instance, investors may perceive that higher dividend yield can provide greater liquidity, ignoring the impact of taxation. This is similar to the findings of Redding (1997) that suggests large investors prefer companies with high liquidity while also preferring to receive dividends. Hence time dependent dividend yields are used in this analysis.

In addition, changes to the volatility of the stock have a large impact on the value of its associated stock options. Therefore using the current volatility is likely to influence the present likelihood of conversion more than past volatility. While implied volatility observed in the market would provide the most accurate value, in most cases such observations were unavailable and historical estimates were used. To obtain the most accurate values, we update each factor of the proxy for the conversion probability $N\left(d_{2}\right)$ on a weekly basis.

\subsection{Cross sectional control variables - Size ${ }_{t}^{i}, B E_{t}^{i}$ and $B e t a_{t}^{i}$}

The study controls for the firm size, the book to market equity and the firm's beta. The Size ${ }_{t}^{i}$ variable is the market value of stock $i$ at time $t$. The market value of the stock is related to liquidity since a larger stock issue has smaller price impact for a given order flow and a smaller bid-offer spread. Stock expected returns are negatively related to size shown in Fama and French (1992) and it can also be viewed as being another proxy for liquidity, see Amihud and Mendelson (1986).

A relationship between expected return and book to market equity $B E_{t}^{i}$ has been shown by Fama and French (1992) due to the functional relation between expected return and the market value of equity. I include the $B E_{t}^{i}$ variable to ensure the regression captures the effects of changes to the book value of assets and its effect on expected returns. Book to market equity value is the ratio of total assets to firm market value. Book value is calculated as the market value of equity plus total assets minus the book value of equity. The book to market values ranged between 0.31 and 3.73 .

The Beta ${ }_{t}^{i}$ variable is included as a measure of risk. The effect of beta is expected to be positive. The values for beta are included to ensure that the effects of systematic risk are accounted for. The betas are calculated against the most representative market capitalisation index for each country. The market portfolios used were the US S\&P500 growth index for US stocks, the Korean S\&P200 growth index for Korean Stocks and the Straits Times Index for Singapore firms. The details of each index are available in appendix A. Betas for each of the 107 stocks analysed varies between 0.89 and 2.91.

\section{Data and Research Method}

\subsection{Market and trading issues}

The data used in this study is taken from three commercial bank databases consisting of a total of 107 publicly listed US, Korean and Singaporean firms who have issued non-callable convertible bonds. All bonds issued are convertible at the discretion 
of the holder any time prior to maturity, are non-callable by the issuer and contain provisions for accrued interest between coupon payments upon early conversion. The option component of each convertible bond therefore contains an American-style exercise feature. Each bond is subject to rigid coupon payments ranging from 3 percent to 8 percent. Each bond had a maturity of three years or more from initial issue and was issued between July 1997 and October 2001. All convertibles provide the option to be converted into the stock at a specified conversion ratio of the issuing company and not another company indirectly. None of the convertibles used are subject to a ratchet feature or similar characteristic that requires the payable yield of the convertible to be increased should dividends on the common stock increase. Only firms whose credit quality as quoted by Standard and Poors and Moody's remained the same throughout the life of the convertible were used in this study. This removes any bias in the results caused by increased trading activity following credit upgrades or downgrades. Over $55 \%$ of the bonds were converted into equity either before or at maturity while the remaining bonds expired out of the money at maturity. No stock splits or rights issues were recorded in the data.

\subsection{Data input definitions}

The ILLIQ ${ }_{t}^{i}$ data was computed at a weekly frequency for each of the 107 stocks over the life of the convertible bonds in the sample. The $I L L I Q_{t}^{i}$ data was transformed into weekly data by computing the arithmetic average of daily data across each week. The range of the $I L L I Q_{t}^{i}$ variable in the sample data was very large. It is therefore possible that any estimated relationship between liquidity and the probability of exercise may be driven by a few extreme realisations of $I L L I Q_{t}^{i}$. To correct for this possibility, the highest and lowest 2.5 percent of observations of $I L L I Q_{t}^{i}$ were discarded from the data. The truncated data set contains weekly $I L L I Q_{t}^{i}$ values that range from 0 to 1.09 for all stocks.

The probability of conversion as measured by $N\left(d_{2}\right)$ requires several inputs that change through time. The volatility, risk free rate and dividend yield must be updated at each data point to obtain a weekly updated measure for $N\left(d_{2}\right)$. The risk free rate is maturity-matched to observed government bond yields at each point in the data set. For instance, the risk free rate used to value a convertible bond that has 5 years to maturity on 13 July 2001 uses the 5-year government bond yield observed on that date. As the maturity of each bond is reduced through time the risk free rate is estimated by interpolating between quoted government bond yields using a cubic spline.

The dividend yield is also updated at each data point to obtain an accurate value for $N\left(d_{2}\right)$. We assume a constant dividend yield measured at each point in the data set for each stock. This is a reasonable assumption given that the dividend yields for $80 \%$ of the stocks in our sample are zero and the remaining $20 \%$ are relatively stable at $1.8-2.9 \%$ over the estimation period.

Finally, at each point in the data set, we assume constant volatility of the stock return out to the maturity of the convertible bond measured using an exponentially weighted moving average (EWMA) model to update the volatility for each weekly data 
point. The EWMA method is more accurate than constant historical volatility measures because it captures changes in volatility translating directly into changes in $N\left(d_{2}\right)$. The EWMA method is less reliable than using observed at the money implied volatilities however the lack of exchange traded options for the stocks used in this analysis does not permit the use of such data.

The EWMA model has weights $\alpha_{i}$ assigned to the continuously compounded return $u_{i}$ that decrease exponentially further back in time, see Engle (1982). The weighting scheme leads to a simple formula for updating volatility estimates,

$$
\sigma_{n}^{2}=\lambda \sigma_{n-1}^{2}+(1-\lambda) u_{n-1}^{2},
$$

where the estimate for the volatility $\sigma_{n}$ on week $n$ is calculated from the previous week's estimate of volatility $\sigma_{n-1}$ on day $n-1$, and the most recent observation on changes in the return of the stock $u_{n-1}$. To obtain the starting value of weekly volatility in the EWMA updating scheme, we use

$$
\sigma_{n}^{2}=(1-\lambda) \sum_{i=1}^{m} \lambda^{i-1} u_{n-1}^{2},
$$

where the number of weekly observations $m$ used for the initial estimation is set to be relatively large $m=100$.

The value for $\lambda$ in the EWMA model controls how responsive the estimate of the weekly volatility is to the most recent observations of the stock return. We apply a value of $\lambda=0.97$ to estimate the weekly volatility. Figure 1 shows the EWMA volatility for one of the more volatile stocks used in this study. The jumps in volatility have an important effect on the value of $N\left(d_{2}\right)$ and are updated to obtain the most accurate value to represent changes in the probability of exercise.

Figure 1

The risk free rate, dividend yield and volatility are updated weekly using the most recently observed data. The weekly value of $N\left(d_{2}\right)$ is computed for each stock over the life of the data series. The data points corresponding to the highest and lowest 2.5 percent for $N\left(d_{2}\right)$ were discarded from the sample to prevent bias from outliers. The final data series for $N\left(d_{2}\right)$ is therefore truncated in a similar way to the $I L L I Q_{t}^{i}$ variable. This procedure provides an accurate picture of the temporal probability of conversion $N\left(d_{2}\right)$ that takes into account changes in the risk free rate, dividend yield and most importantly, volatility. From these assumptions, the probability of conversion as measured by $N\left(d_{2}\right)$ ranges from 0.0015 to 1.000 for all stocks used in the study. 


\section{Results}

\subsection{Liquidity and the probability of conversion}

The empirical tests use a two-pass regression method on the estimates in equation (9). In the first pass all firms are grouped within in a single portfolio. The $I L L I Q_{t}^{i}$ variable was regressed on values of $N\left(d_{2}\right)$, book to market equity $B E_{t}^{i}$ and firm beta Beta ${ }_{t}^{i}$ over the estimation period

$$
I L L I Q_{t}^{i}=\alpha_{0}+\alpha_{1} N\left(d_{2}\right)_{t}^{i}+\alpha_{2} B E_{t}^{i}+\alpha_{3} B e t a_{t}^{i}+\varepsilon_{i} .
$$

Table 1

Table 1 provides the regression results. It is evident that a strong positive relationship exists between liquidity and the probability of conversion, as measured by $N\left(d_{2}\right)$. The results are statistically significant at the 1 percent level. The book to market equity and firm beta has no significant impact at the 1 percent level.

In order to isolate the impact of the probability of conversion on liquidity, the differences in liquidity between stocks whose bonds have a high conversion probability compared with those with little chance is examined. I conduct a second pass regression which groups the same set of firms into four portfolios based on the likelihood of exercise of the convertible bonds in the final 12 months of each bond's life. The general regression remains the same however the firms are sorted into four portfolios based on the value of $N\left(d_{2}\right)$ observed over the final 12 months of the life of each bond. The first portfolio consists of firms where the probability of conversion is greater than $75 \%$, that is $N\left(d_{2}\right)>0.75$. The second portfolio consists of firms where the probability is between $50-75 \%$, that is $0.5<N\left(d_{2}\right)<0.75$. The third portfolio groups firms whose probability is between $25-50 \%$, that is $0.25<N\left(d_{2}\right)<0.5$. The fourth portfolio groups firms who have issued bonds with little chance of conversion, that is $N\left(d_{2}\right)<0.25$. Firms that switched from one portfolio to the other are excluded from the second pass regression. By sorting on conversion probabilities, we are able to maximise the cross sectional variation of $I L L I Q_{t}^{i}$ to be explained by $N\left(d_{2}\right)$.

In addition, Amihud (2002) examines the relationship between returns and liquidity in a time-varying framework and the results show a significantly positive relationship between expected market illiquidity and ex ante stock excess return, which suggests that expected stock excess returns are, in part, a premium for stock illiquidity. The effects of illiquidity on stock excess returns differ across stocks by their size over time. This suggests that share illiquidity affects smaller stocks more strongly than larger stocks. I therefore conduct a second pass regression on the same set of firms grouped into four portfolios by size, quartiles 1 to 4 , to detect the impact of conversion probability on stock liquidity for small and large firms. The results are presented in Table 2. 
The set of results in Table 2 suggests that the probability of conversion is statistically significantly related to the liquidity of stocks against which convertibles are issued. The effect is more pronounced for stocks with a high probability of conversion and also for smaller stocks. The insignificant results for firms constituting the $N\left(d_{2}\right)<$ 0.25 portfolio suggests that firms with a low probability of conversion are unrelated to stock illiquidity. It is likely that the behaviour of stocks with these convertible bonds has little impact on the liquidity of the stock and since there is only a small chance they will be converted, other effects such as firm size and performance will have a greater impact on underlying liquidity.

The book to market equity value $B E_{t}^{i}$ is significant for the portfolio of all stocks, all portfolios of varying conversion probabilities and the three smaller quartile stock portfolios. This suggests that the expected return as reflected in the $B E_{t}^{i}$ variable has a more significant effect on liquidity for smaller stocks and stocks with a higher than average probability of conversion. However the $B E_{t}^{i}$ results are very significant for stocks with little chance of conversion, $N\left(d_{2}\right)<0.25$, suggesting that investors are treating all convertibles as straight debt and any illiquid effects are a result of firm size and performance. Perhaps surprisingly beta is insignificant for all portfolios.

\subsection{Cross sectional model}

I construct a cross sectional model by regressing stock characteristics against $I L L I Q_{t}^{i}$ as in equation (2). The model is estimated for the two years immediately prior to maturity for each bond generating 104 sets of coefficients. I choose the final two years of each bond since greater changes in $N\left(d_{2}\right)$ against $I L L I Q_{t}^{i}$ due to the time decay of the option can be observed in this period. The mean and standard error of the 104 estimated coefficients are calculated for each stock characteristic followed by a t-test of the null hypothesis of zero mean. The results, presented in Table 3 strongly support the hypothesis that illiquidity is strongly related to the probability of conversion after controlling for firm size, book to market equity and firm beta.

Table 3

As shown in Table 3 it is apparent that a strong positive relationship exists between the probability of conversion and stock liquidity. The highly significant values for $N\left(d_{2}\right)$ across each regression confirms that stock illiquidity and conversion probabilities are inversely related, or conversely liquidity and conversion probability are directly related. The $B E_{t}^{i}$ and $B e t a_{t}^{i}$ parameters are statistically insignificant across the spectrum of stocks used in this study. Firm size is statistically significant for each of the regressions. This is because firm size can be viewed as a coarse measure of illiquidity as shown in Amihud and Mendelson (1986) and therefore the inverse relationship between Size $_{t}^{i}$ and $I L L I Q_{t}^{i}$ is evident. In addition, small illiquid stocks should experience stronger 
effects of market illiquidity through a greater positive effect of expected illiquidity on ex ante return and a more negative effect of unexpected illiquidity on contemporaneous return. For large liquid stocks both effects should be weaker since these stocks become relatively more attractive in times of tighter market liquidity.

From these results I conclude that a strong positive relationship exists between liquidity and the probability of conversion, as measured by $N\left(d_{2}\right)$ along with a direct and positive relationship between liquidity and firm size.

\subsection{Reasons for Liquidity Changes - Changes in capital structure and share volume}

The exercise of the convertibles allows us to isolate the reasons why liquidity may change as the probability of conversion changes. For a bond that is approaching expiry with a high probability of conversion, the liquidity of the stock is expected to increase. Figure 2 shows the traded volume of stock against the share price and the maturity date for the entire portfolio of stocks. A weak relationship can be observed between volume traded and share price changes, although this relation is not consistent over the period. When the volume and stock returns are combined to measure liquidity through the ILLIQ ${ }_{t}^{i}$ parameter, the correlation between stock liquidity and $N\left(d_{2}\right)$ is much clearer.

Figure 2

Figure 3 shows the liquidity against the conversion probability for the entire portfolio of stocks. Increases in the share price clearly translate into increases in the probability of conversion, however other factors such as volatility and the time decay of the option component of the convertible have an effect.

Figure 3

I propose that this change is due to the anticipated trade of a higher volume of shares, should the holder wish to immediately sell the newly converted stock, and is also due to the expected change in the capital structure of the firm. Given that the firm will have a significantly lower debt/equity ratio upon conversion, this may heighten demand for the stock resulting in even greater liquidity.

Price reactions to convertible debt security offer announcements are negative and statistically significant, see Lewis, Rogalski and Seward (1999). A major feature of convertible debt issues is the impact of share dilution upon a likely conversion of the debt to equity. While investors will naturally incorporate the likely impact of additional shares being issued following conversion into the share price, there may be endogenous changes in the liquidity of the stock. This could be the result of a sudden increase in the number of tradable shares available, significant changes in capital structure and dividend payment expectations. It is clear from the research of Lewis, Rogalski and Seward (1999) that some form of share dilution upon conversion is expected to have some impact on returns. However the impact of the positive effects from a change in capital structure and increased volume of shares is expected to override the negative effects of an expected large block trade of shares. This expectation manifests itself in the exercise probability of convertibles nearing expiry. For all convertible instruments used in this study, the 
proportion of shares to the pre-conversion float is less than 12 percent. Therefore only small effects from share price dilution are expected in these results. For larger proportions being converted upon expiry distortions in liquidity will probably be observed.

For a bond that is approaching expiry with a low probability of conversion, the expected change in liquidity is perhaps less clear. The expiry of the convertible bond can be refinanced with another convertible or straight bond, resulting in minimal change to the capital structure of the firm. No anticipated change in the volume of shares available in the market following conversion should therefore result in minimal impact on liquidity for a convertible that has a low exercise probability.

The following analysis searches for the reasons why liquidity increases as the conversion probability increases. The basic specification estimates are

$$
I L L I Q_{t}^{i}=\beta_{0}+\beta_{1} E C S_{t}^{i}+\beta_{2} V O L_{t}^{i}+\varepsilon_{i}
$$

where

$$
E C S_{t}^{i}=E_{t}\left[\frac{D_{T}^{i}}{D_{T}^{i}+E_{T}^{i}}\right]
$$

represents the anticipated new capital structure of the firm using the debt $D$ and equity $E$ at conversion date $T$, and

$$
\operatorname{VOL}_{t}^{i}=E_{t}\left[\frac{\operatorname{conv}_{T}^{i}}{\operatorname{total}_{\tau<T}^{i}}\right]
$$

represents the ratio of the number of shares converted to the existing total ordinary shares available for trade for the $i$-th firm. The results from this regression are presented in Table 4.

Table 4

Table 4 shows that both the expected change in the proportion of shares available for trade and the expected change in the debt equity ratio will result in greater liquidity. However the effect of the expected increase in tradeable volume is greater for most portfolios of stocks. This suggests that stock liquidity increases in anticipation of the expected market capitalisation increase upon conversion for firms with a higher probability of conversion. As fund managers rebalance their portfolios in anticipation of the change in the total equity of firms with a high chance of conversion, so the liquidity appears to increase. The expected changes are also greater for smaller firms as evident from the results. The results for the portfolio of stocks with little chance of conversion, $N\left(d_{2}\right)<0.25$, are insignificant. 


\section{Discussion}

The results indicate that as the probability of exercise of a convertible bond issued against a particular stock increases, the liquidity of the stock itself appears to also increase. By incorporating time to expiry, stock price volatility using an EWMA model and dividend payments in the $N\left(d_{2}\right)$ component derived from the Black and Scholes model, the interaction of these factors help predict with greater accuracy the probability of conversion through time. There is a clear relationship between average liquidity and the average likelihood of conversion of a convertible for the firms used in this study. There are some issues to consider however when each factor is examined in isolation.

From Constantinides and Scholes (1980), stocks with higher volatility should result in lower returns due to the tax trading option. Taxes have not been considered in this study however it is expected that their impact on the convertibility option is small, particularly for the markets used in this study.

Two bond yield premiums are known to have a positive temporal effect on stock returns through time, see Fama and French (1989). The default yield premium, which is the excess yield on corporate bonds and the term yield premium, which is the difference between long-term and short-term bond yields are the main causes. Amihud (2002) found that the effect of the default premium varies significantly with firm size. Since the default premium signifies default risk and future adverse economic conditions, it should have a greater effect on the expected return of smaller firms. Unfortunately we are unable to test the hypothesis in this study due to data constraints, however we control for this indirectly by selecting firms whose credit rating remains constant throughout. This may induce some survivor bias in the results however market observed credit spreads for all firms used in this study are unavailable.

A financially leveraged firm tends to issue convertible debt only if management is relatively optimistic about its future share price performance, see Lewis, Rogalski and Seward (1999). Convertible debt issue announcements produce a significant negative stock price reaction that is consistent with the backdoor-equity hypothesis.

\section{Concluding Remarks}

In this paper I provide evidence that there is a positive relationship between the probability of conversion of a convertible bond issued on a company's stock, and the liquidity of the stock itself. I use the daily ratio of absolute stock return to its dollar volume, averaged over a weekly frequency as a proxy for the liquidity of the stock and $N\left(d_{2}\right)$ as a proxy for the probability of conversion. In general I find that as the probability of conversion increases, the liquidity of the stock also tends to increase. This effect is more pronounced for larger firms and firms with a higher than average chance of conversion in the 12 months prior to debt maturity. This result is significant across all 107 stocks measured in this study. I also conduct a cross section regression to measure the effect of conversion probability on liquidity for each firm, while controlling for firm size, book to market equity and firm beta. The results from this model confirm the direct relationship between liquidity and conversion probability. Both the expected change in the proportion of shares available for trade and the change in the debt equity ratio are 
identified as the reasons why liquidity is expected to increase. The expected increase in the volume of tradeable shares is the primary cause of the increase in liquidity. 


\section{References}

Amihud, Y., 2002, Illiquidity and stock returns: Cross section and time series effects, Journal of Financial Markets, 5, 31-56.

Amihud, Y. and Mendelson, H., 1986, Asset pricing and the bid ask spread, Journal of Financial Economics, 17, 223-249

Black, F., and Scholes, M., 1973, The pricing of options and corporate liabilities, Journal of Political Economy, 81, 637-659.

Breen, W.J., Hodrick, L.S. and Korajczyk, R.A., 2002, Predicting equity liquidity, Management Science, 48 (4), 470-483.

Chordia, T., Subrahmanyan, A., and Anshuman, V.R., 2001, Trading activity and expected stock returns, Journal of Financial Economics, 48, 3-32.

Constantinides, G.M. and Scholes, M.S., 1980, Optimal liquidation of assets in the presence of personal taxes: implications for asset pricing, Journal of Finance, 35, 439443.

Cox, J., Ross, S. and Rubenstein, M., 1979, Option pricing: A simplified approach, Journal of Financial Economics, 7, 229-264.

Datar, V.T., Naik, N.Y. and Radcliffe, R., 1998, Liquidity and stock returns: An alternative test, Journal of Financial Markets, 1, 203-219.

Duffie, D. and Singleton. K, 1999, Modelling term structures of defaultable bonds, Review of Financial Studies, 12, 687-720.

Engle, R., 1982, Autoregressive conditional heteroscedasticity with estimates of the variance of UK inflation, Econometrica, 50, 987-1008.

Fama, E.F. and MacBeth, J.D., 1973, Risk, return and equilibrium: empirical tests, Journal of Political Economy, 81, 607-636.

Fama, E.F., and French, K.R., 1989, Business conditions and expected returns on stocks and bonds, Journal of Financial Economics, 25, 23-49.

Fama, E.F., and French, K.R., 1992, The cross section of expected stock returns, Journal of Finance, 47, 427-465.

Haugen, R.A., and Baker, N.L., 1996, Commonality in the determinants of expected stock returns, Journal of Financial Economics, 41, 401-439. 
Hull, J.C., 2000, Options, Futures and Other Derivatives, Prentice-Hall, New Jersey.

Ingersoll, J. E., 1977, A contingent claims valuation of convertible securities, Journal of Financial Economics, 4(3), 289-322.

Lewis, C., Rogalski, R., and Seward, J., 1999, Is convertible debt a substitute for straight debt or common equity?, Financial Management 28:3, 5-27.

Merton, R.C., 1973, Theory of Rational Option Pricing, Bell Journal of Economics and Management Science, 4, 141-183.

Pereira, J.P. and Zhang, H.H., 2003, The liquidity premium in a dynamic model with price impact, Working Paper, University of North Carolina.

Redding, L.S., 1997, Firm size and dividend payouts, Journal of Financial Intermediation, 6, 224-248.

Rendleman, R., and Bartter, B., 1979, Two state option pricing, Journal of Finance, 34, 1092-1110.

Stein, T., 1992, Convertible bonds as backdoor equity financing, Journal of Financial Economics, August, 3-21. 


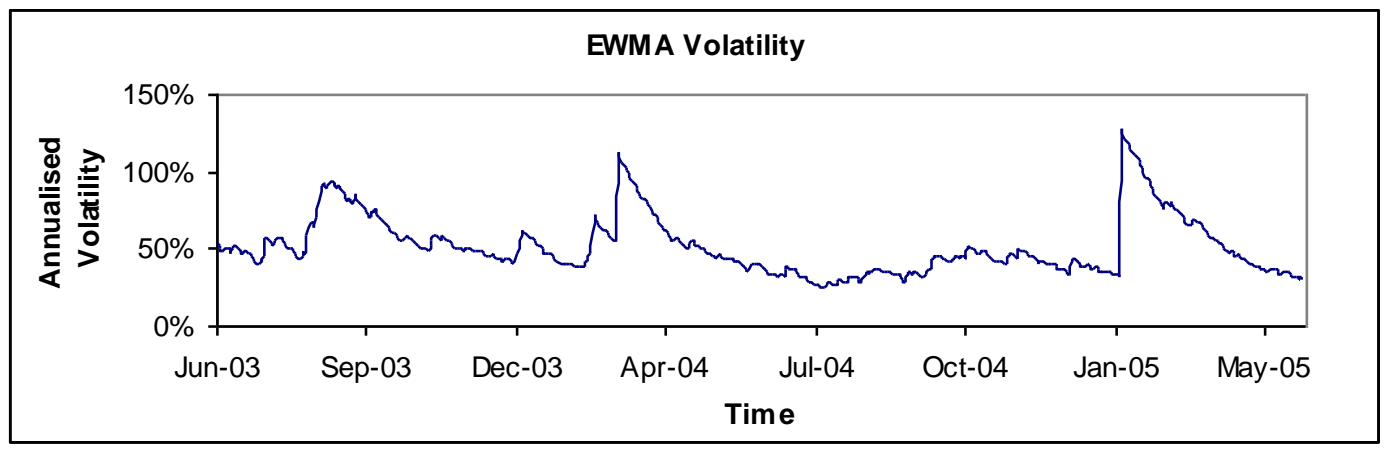

Figure 1. Weekly exponentially weighted moving average (EWMA) volatility for a firm chosen from the sample estimated over a two-year period. The EWMA updating scheme is used as a proxy for implied stock volatility to evaluate the probability of conversion measured using $N\left(d_{2}\right)$ over the estimate period. 


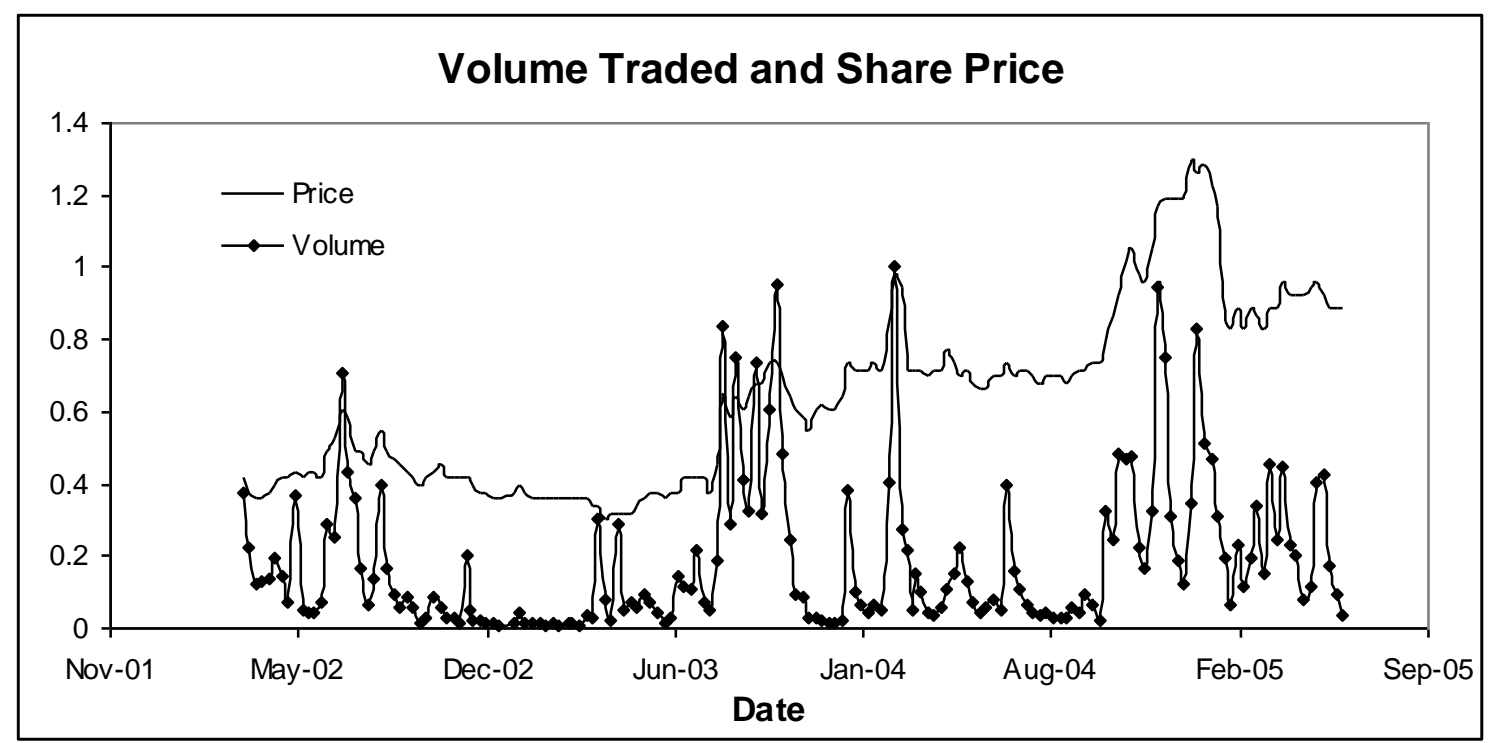

Figure 2: Traded volume of stock against the share price for a portfolio of firms that have issued convertibles against their own stock. Both sets of data have been normalised for ease of comparison.

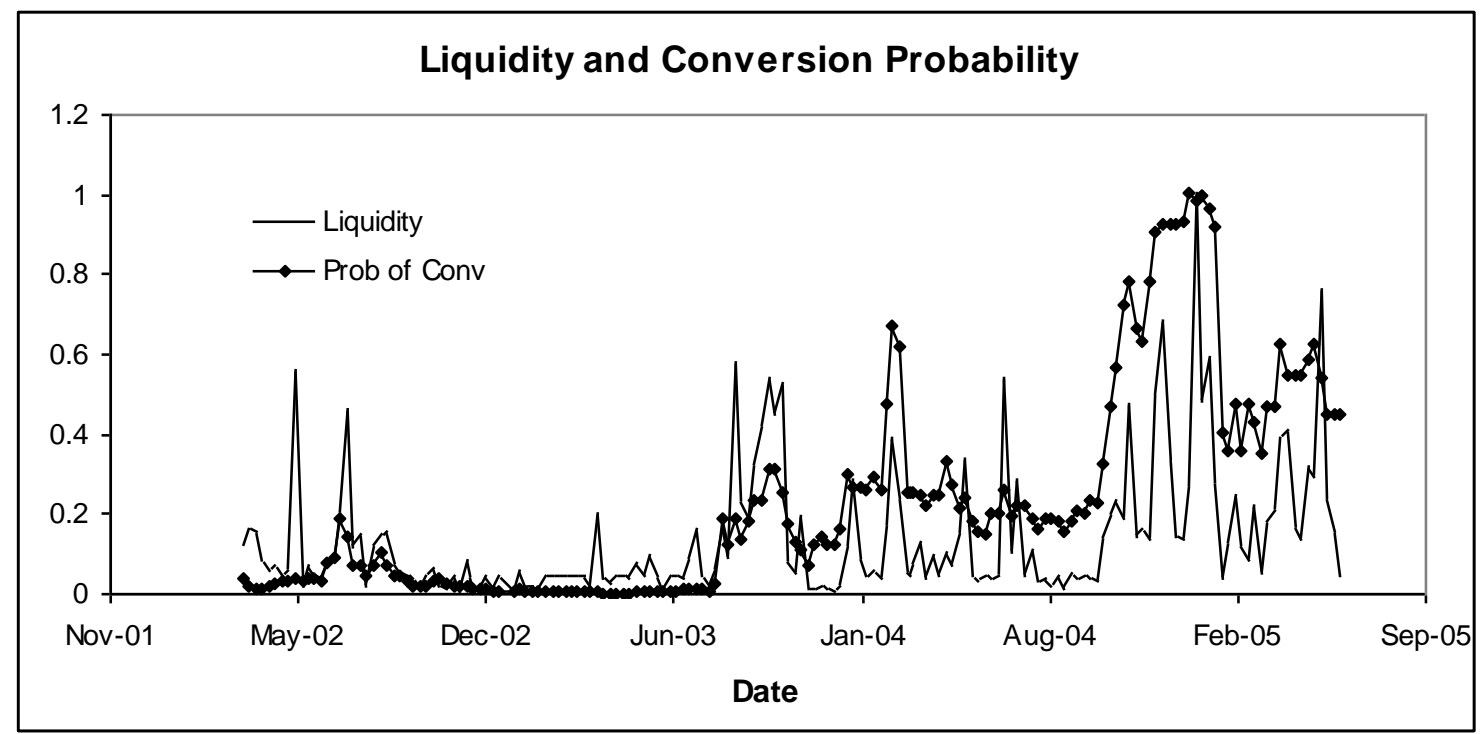

Figure 3: Liquidity against the probability of conversion for a portfolio of firms that have issued convertibles against their own stock. Liquidity is measured as the inverse of $I L L I Q_{t}^{i}$ and the conversion probability is measured using $N\left(d_{2}\right)$. Both sets of data have been normalised for ease of comparison. 


\begin{tabular}{ccccc}
\hline Constant & $N\left(d_{2}\right)$ & $B E_{t}^{i}$ & Beta $_{t}^{i}$ & Adjusted $R^{2}$ \\
\hline 0.126 & -0.181 & & & 0.843 \\
$(9.846)$ & $(4.608)$ & & & \\
0.022 & -0.075 & 0.187 & & 0.821 \\
$(2.379)$ & $(3.841)$ & $(1.858)$ & -0.032 & 0.792 \\
0.123 & -0.106 & & $(-1.171)$ & \\
$(4.273)$ & $(5.891)$ & & 0.021 & 0.779 \\
-0.418 & -0.164 & 1.325 & $(0.548)$ & \\
$(1.485)$ & $(3.891)$ & $(1.931)$ & & \\
\hline
\end{tabular}

Table 1: Regression of illiquidity on conversion probability and other firm characteristics.

Regression of stock illiquidity $I L L I Q_{t}^{i}$ on the probability of conversion of convertible bonds issued against the stock $N\left(d_{2}\right)$, the book to market equity value $B E_{t}^{i}$ and firm beta $\operatorname{Beta}_{t}^{i}$. The table presents the means of the coefficients and the t-statistics are in parentheses. The portfolio of all stocks includes the stock characteristics of all 107 firms measured over the period in which the convertible bond is issued prior to maturity or exercise. The illiquidity measure used $I L L I Q_{t}^{i}$ is ratio of absolute daily stock return to its dollar volume averaged for each week. The probability of conversion is measured using $N\left(d_{2}\right)$ and is updated using market observed values for the risk free rate, dividend yield and an exponentially weighted moving average (EWMA) updating scheme for stock volatility. Book-to-market equity value is the ratio of total assets to firm market value. Book value is calculated as the market value of equity plus total assets minus the book value of equity. Beta is the firm beta measured as the covariance of the stock and the market portfolio divided by the variance of the market portfolio. The market portfolio is the best representative broad based market capitalisation index for Singapore, Korea and US firms respectively. 


\begin{tabular}{|c|c|c|c|c|c|c|c|c|c|}
\hline Variable & $\begin{array}{c}\text { All } \\
\text { stocks }\end{array}$ & $N\left(d_{2}\right)>0.75$ & $0.75>N\left(d_{2}\right)>0.5$ & $0.5>N\left(d_{2}\right)>0.25$ & $N\left(d_{2}\right)>0.25$ & $\begin{array}{l}\text { Quartile 1 } \\
\text { (largest) }\end{array}$ & Quartile 2 & Quartile 3 & $\begin{array}{l}\text { Quartile } 4 \\
\text { (smallest) }\end{array}$ \\
\hline \multirow[t]{2}{*}{ Constant } & -0.418 & -0.217 & -0.434 & -0.427 & -0.019 & -0.484 & -0.231 & -0.089 & -0.410 \\
\hline & $(1.485)$ & $(2.762)$ & $(1.116)$ & $(1.287)$ & $(0.547)$ & $(2.767)$ & $(1.987)$ & $(1.340)$ & $(1.672)$ \\
\hline \multirow{2}{*}{$N\left(d_{2}\right)$} & -0.164 & -0.249 & -0.226 & -0.148 & -0.070 & -0.652 & -0.298 & -0.334 & -0.219 \\
\hline & $(3.891)$ & $(5.772)$ & $(4.778)$ & $(3.343)$ & $(1.882)$ & $(5.667)$ & $(4.892)$ & $(3.991)$ & (3.361) \\
\hline \multirow[t]{2}{*}{$\mathrm{BE}$} & 1.325 & 1.194 & 0.790 & 0.981 & 2.101 & 0.882 & 1.017 & 0.887 & 0.790 \\
\hline & $(1.931)$ & $(2.466)$ & $(2.050)$ & $(1.326)$ & $(3.210)$ & (1.898) & $(0.991)$ & $(0.845)$ & $(0.549)$ \\
\hline \multirow[t]{2}{*}{ Beta } & 0.021 & 0.011 & 0.066 & 0.004 & 0.101 & 0.204 & 0.108 & 0.038 & 0.045 \\
\hline & $(0.548)$ & $(1.098)$ & $(0.510)$ & $(0.659)$ & $(0.228)$ & $(0.989)$ & $(0.078)$ & $(0.552)$ & $(0.434)$ \\
\hline Adjusted R² & 0.722 & 0.853 & 0.775 & 0.666 & 0.594 & 0.815 & 0.827 & 0.713 & 0.703 \\
\hline
\end{tabular}

\section{Table 2: Cross sectional regression of illiquidity on conversion probability and other firm characteristics.}

Cross sectional regressions of illiquidity on the probability of conversion of convertible bonds issued against the stock, and the stock characteristics of book to market equity $B E_{t}^{i}$ and firm beta $B_{e t}{ }_{t}^{i}$. The portfolio of all stocks includes the stock characteristics of all 107 firms measured over the period in which the convertible bond is issued prior to maturity or exercise. The illiquidity measure used $I L L I Q_{t}^{i}$ is ratio of absolute daily stock return to its dollar volume averaged for each week. The probability of conversion is measured using $N\left(d_{2}\right)$ and is updated using market observed values for the risk free rate, dividend yield and an exponentially weighted moving average (EWMA) updating scheme for stock volatility. Book-to-market equity value is the ratio of total assets to firm market value. Book value is calculated as the market value of equity plus total assets minus the book value of equity. Beta is the firm beta measured as the covariance of the stock and the market portfolio divided by the variance of the market portfolio. The market portfolio is the best representative broad based market capitalisation index for Singapore, Korea and US firms respectively. 


\begin{tabular}{|c|c|c|c|c|c|}
\hline Constant & $N\left(d_{2}\right)$ & Size $_{t}^{i}$ & $B E_{t}^{i}$ & $\operatorname{Beta}_{t}^{i}$ & Adjusted $R^{2}$ \\
\hline $\begin{array}{c}0.226 \\
(7.856)\end{array}$ & $\begin{array}{c}-0.127 \\
(3.608)\end{array}$ & & & & 0.813 \\
\hline $\begin{array}{c}0.168 \\
(4.702)\end{array}$ & $\begin{array}{c}-0.137 \\
(3.984)\end{array}$ & $\begin{array}{c}-0.042 \\
(2.891)\end{array}$ & & & 0.834 \\
\hline $\begin{array}{c}0.022 \\
(2379)\end{array}$ & $\begin{array}{l}-0.075 \\
(3841)\end{array}$ & & $\begin{array}{c}0.187 \\
(1858)\end{array}$ & & 0.772 \\
\hline $\begin{array}{c}0.123 \\
(4.273)\end{array}$ & $\begin{array}{l}-0.106 \\
(5.891)\end{array}$ & & & $\begin{array}{c}-0.032 \\
(-1.171)\end{array}$ & 0.790 \\
\hline $\begin{array}{c}0.097 \\
(2.087)\end{array}$ & $\begin{array}{l}-0.219 \\
(3.099)\end{array}$ & $\begin{array}{l}-0.056 \\
(2.443)\end{array}$ & $\begin{array}{c}0.016 \\
(0.576)\end{array}$ & & 0.801 \\
\hline $\begin{array}{l}-0.418 \\
(1.485)\end{array}$ & $\begin{array}{c}-0.164 \\
(3.891)\end{array}$ & & $\begin{array}{c}1.325 \\
(1.931)\end{array}$ & $\begin{array}{c}0.021 \\
(0.548)\end{array}$ & 0.721 \\
\hline $\begin{array}{c}0.202 \\
(1.219)\end{array}$ & $\begin{array}{l}-0.098 \\
(2.882)\end{array}$ & $\begin{array}{c}-0.110 \\
(2.088)\end{array}$ & $\begin{array}{c}0.032 \\
(0.242)\end{array}$ & $\begin{array}{c}0.120 \\
(1.656)\end{array}$ & 0.697 \\
\hline
\end{tabular}

\section{Table 3: Cross sectional regression of stock illiquidity on conversion probability and other firm characteristics.}

Cross sectional regression of stock illiquidity $I L L I Q_{t}^{i}$ on the probability of conversion of convertible bonds issued against the stock $N\left(d_{2}\right)$ and the other stock characteristics of firm size Size $e_{t}^{i}$, book to market equity $B E_{t}^{i}$ and firm beta Beta ${ }_{t}^{i}$. The table presents the means of the coefficients and the t-statistics. The cross section of stocks includes the stock characteristics of all 107 firms measured over the period in which the convertible bond is issued prior to maturity or exercise. The illiquidity measure used $I L L I Q_{t}^{i}$ is ratio of absolute daily stock return to its dollar volume averaged for each week. The probability of conversion is measured using $N\left(d_{2}\right)$ and is updated using market observed values for the risk free rate, dividend yield and an exponentially weighted moving average (EWMA) updating scheme for stock volatility. Book-to-market equity value is the ratio of total assets to firm market value. Book value is calculated as the market value of equity plus total assets minus the book value of equity. Beta is the firm beta measured as the covariance of the stock and the market portfolio divided by the variance of the market portfolio. The market portfolio is the best representative broad-based market capitalisation index for Singapore, Korea and US firms respectively. 


\begin{tabular}{|c|c|c|c|c|c|c|c|c|c|}
\hline Variable & $\begin{array}{c}\text { All } \\
\text { stocks }\end{array}$ & $N\left(d_{2}\right)>0.75$ & $0.75>N\left(d_{2}\right)>0.5$ & $0.5>N\left(d_{2}\right)>0.25$ & $N\left(d_{2}\right)>0.25$ & $\begin{array}{l}\text { Quartile 1 } \\
\text { (largest) }\end{array}$ & Quartile 2 & Quartile 3 & $\begin{array}{l}\text { Quartile } 4 \\
\text { (smallest) }\end{array}$ \\
\hline \multirow[t]{2}{*}{ Constant } & -0.227 & -0.342 & -0.229 & -0.426 & 0.067 & -0.229 & -0.410 & -0.623 & -0.264 \\
\hline & $(1.485)$ & $(1.998)$ & $(1.045)$ & $(1.452)$ & $(0.342)$ & (1.112) & $(0.674)$ & $(1.248)$ & (1.982) \\
\hline \multirow{2}{*}{$E C S_{t}^{i}$} & -0.325 & -0.547 & -0.490 & -0.210 & 0.034 & -0.109 & -0.323 & -0.336 & -0.326 \\
\hline & $(2.931)$ & $(2.445)$ & $(2.288)$ & $(2.378)$ & $(0.671)$ & $(2.234)$ & $(2.096)$ & $(2.797)$ & (3.001) \\
\hline \multirow{2}{*}{$V O L_{t}^{i}$} & -1.164 & -1.873 & -2.099 & -1.089 & -0.309 & -1.003 & -0.562 & -1.865 & -1.992 \\
\hline & $(3.891)$ & $(4.554)$ & $(2.432)$ & $(4.385)$ & $(1.223)$ & $(2.887)$ & $(2.781)$ & $(3.589)$ & (3.779) \\
\hline Adjusted $\mathrm{R}^{2}$ & 0.912 & 0.943 & 0.875 & 0.686 & 0.394 & 0.785 & 0.792 & 0.760 & 0.814 \\
\hline
\end{tabular}

\section{Table 4: Cross sectional of regression of illiquidity on the expected change in capital structure and tradeable share volume.}

Cross sectional regressions of illiquidity $I L L I Q_{t}^{i}$ on the probability of conversion of convertible bonds issued against the stock $N\left(d_{2}\right)$, the expected change in capital structure $E C S_{t}^{i}$ and the expected proportion of shares available for trade upon conversion $V O L_{t}^{i}$. The portfolio of all stocks includes the stock characteristics of all 107 firms measured over the period in which the convertible bond is issued prior to maturity or exercise. The illiquidity measure used $I L L I Q_{t}^{i}$ is ratio of absolute daily stock return to its dollar volume averaged for each week. The probability of conversion is measured using $N\left(d_{2}\right)$ and is updated using market observed values for the risk free rate, dividend yield and an exponentially weighted moving average (EWMA) updating scheme for stock volatility. The firms are used are from Singapore, Korea and the US. 


\section{Appendix A - Market Characteristics of Singapore and Korea}

\section{A.1 Singapore}

\section{A.1.1 Features of the Singapore Stock Exchange}

The Singapore Stock Exchange (SGX) lists the stocks of over 500 companies on either the SGX Mainboard or the SGX SESDAQ. The SGX operates a fully automated order driven trading system known as the Central Limit Order Book (CLOB). Limit and market orders are executed in a continuous auction between 09:00 and 12:30 and then between 14:00 and 17:00 Monday to Friday, on the basis of price then time priority. There is a pre-open routine from 08:30 to 09:00 and a pre-close routine from 17:00 to 17:06. Shares are mainly traded in board lots of 1000 units but the trading of odd units is allowed. The Unit Share Market enables the trading of odd lots in any quantity less than one board lot of the underlying share in the Ready Market. For example, for a buy order of $1060 \mathrm{XYZ}$ shares, 1000 shares will be executed on the Ready Market and the remaining 60 shares will be executed on the Unit Share Market. Amalgamation of trades between the Ready and Unit Share markets is possible, whereby trades executed in the two markets for the same underlying share can be consolidated in a single contract. Board lot trading on the existing Ready Market is maintained for those who wish to continue trading in the designated board lot sizes.

The minimum bid size for listed companies trading at a share price less than SGD $\$ 1$ is SGD\$0.005, and between SGD\$1 and SGD\$3, the minimum bid size is SGD\$0.01. All stocks examined in this paper currently trade at a price of less than SGD\$3.00. The small tick sizes used by the Singapore Exchange are expected to remove most of the noise in our estimation. In addition to brokerage fees, a clearing fee of 0.05 percent on the value of the contract, up to a maximum of SGD\$200 is payable. No foreign exchange controls or capital gains tax is payable on the securities traded by non-residents. There are no limitations on the repatriation of income, capital and capital gains.

\section{A.1.2 Straits Times Index}

The index used to represent the market portfolio is the Straits Times Index (STI). The STI is a modified market capitalisation-weighted index comprised of the most heavily weighted and active stocks traded on the Stock Exchange of Singapore. The Straits Times Newspaper of Singapore compiles the STI. The index was developed with a base value of 885.26 as of August 28, 1998.

\section{A.2 Korea}

\section{A.2.1 Features of the Korean Stock Exchange}

The Korea Stock Exchange (KRX)

Orders submitted by investors are matched according to the price and time priority, and are executed by means of either periodic call auction or continuous action. Periodic call 
auction is utilized to determine an impartial fair price after a period of trade suspension or in cases where detailed information on the securities markets is lacking or unavailable. The continuous auction is a method used to determine price during regular trading hours after the opening price has been determined. This method matches a bid and offer bilaterally and when a new bid or offer enters into the system, it is matched with any of the existing offers or bids compiled in the order book according to price priority and time priority. If the lowest bid and highest offer can be executed, a priority is given to the order received earlier. The trading hours are 09:00-15:00 for the regular session, and 07:30-08:30 and 15:10-18:00 for the pre-hours session and the after-hours sessions respectively. Trading units are 10 shares (in case of stocks), and 1 share for stocks whose closing prices on previous day are higher than KRW 100,000. In cases where difficulties in the normal trade execution of an issue is anticipated because of drastic increase in the number of negotiable shares, the trading unit is adjusted upward. Odd lots with quantities of less than 10 shares can be traded in the pre-hours and after-hours sessions. The quotation price unit method is broken into six different quotation price units are used depending on the price of shares. Most market data are available on real-time basis through the KRX computer system.

\section{A.2.2 Korean KRX100}

The index used to represent the market portfolio is the KRX 100. This index chooses its constituents from both the main board stock market and the Kosdaq market. The constituents of the KRX 100 are blue chip stocks representing the KRX market chosen based on market capitalization, trading value, profitability, stability and soundness. To ensure that KRX100 accurately represents the market free-float weighted and capitalization limit methods are adopted. 